\title{
Association of anemia with rehabilitation outcomes for subacute geriatric rehabilitation patients in a secondary hospital in malaysia
}

\author{
Mann Leon Chin ${ }^{\mathrm{a},{ }^{*}}$, Christopher WS Chan ${ }^{\mathrm{b}}$, Huey Ee Chong ${ }^{\mathrm{c}}$, Wee Kooi Cheah ${ }^{\mathrm{b}, \mathrm{c}}$ \\ ${ }^{a}$ Department of Internal Medicine, Hospital Pulau Pinang, Ministry of Health, Pulau Pinang, Malaysia. \\ ${ }^{b}$ Clinical Research Centre, Hospital Taiping, Ministry of Health, Perak, Malaysia. \\ 'Department of Medicine, Hospital Taiping, Ministry of Health, Perak, Malaysia.
}

\begin{abstract}
Background: To evaluate the effects of anemia on rehabilitation outcomes for geriatric subjects in the Taiping Hospital subacute geriatric rehabilitation ward.

Methods: This was a retrospective study with 126 subjects that compared the change in the modified Barthel Index score of anemic and non-anemic subjects.

Results: In the study, $43.7 \%$ of subjects were anemic. Among anemic subjects, $45.5 \%$ were Malay, $38.2 \%$ were Chinese, $14.5 \%$ were Indian, and $1 \%$ were others. The median (Interquartile (IQR)) modified Barthel Index (MBI) on admission for anemic and non-anemic subjects was insignificantly different, at $47(29,63)$ and 36 $(21,59)$, respectively $(P=0.059)$. The median (IQR) of MBI improvement for non-anemic subjects was found to be significantly higher than for anemic subjects, which were $14(5,26)$ and $8(1,18 ; P=0.021)$. Subjects with hemoglobin $(\mathrm{hb}) \geq 9 \mathrm{~g} / \mathrm{dL}$ were significantly associated with MBI improvement of more than $20, P=0.009$. Simple linear regression found that the $P$-values were not significant for albumin, creatinine, the Charlson comorbidity index, or the clinical frailty scale; hence, they were not significantly associated with rehabilitation outcome.

Conclusions: The study suggested that non-anemic subjects showed significant MBI improvement. Our study also suggested that judicious practices to target a hb threshold of $9 \mathrm{~g} / \mathrm{dL}$ might be able to improve a subject's functional outcome. These results should encourage further research with a larger elderly population to provide insights and awareness for the need to treat anemia in rehabilitation subjects.

Keywords: Geriatric, anemia, rehabilitation, modified barthel index
\end{abstract}

\section{Introduction}

Anemia is a common disease in the elderly population worldwide. According to the World Health Organisation (WHO), the definition of anemia is hemoglobin (hb) less than $13 \mathrm{~g} / \mathrm{dL}$ in men, less than $12 \mathrm{~g} / \mathrm{dL}$ in non-pregnant women, and less than $11 \mathrm{~g} / \mathrm{dL}$ in pregnant women [1]. In Malaysia, the prevalence of anemia among communitydwelling people older than 60 years of age was $35.3 \%$

\footnotetext{
* Corresponding author: Mann Leon Chin

Mailing address: Department of Internal Medicine, Pulau Pinang Hospital, Jalan Residensi, 10990 George Town, Pulau Pinang, Malaysia.

Email: drleoncm@gmail.com

Received: 01 September 2021 / Accepted: 03 November 2021
}

[2]. Geriatric inpatients have a higher anemia prevalence than community-dwelling older people [3]. In Singapore, the anemia prevalence in geriatric inpatients is as high as $57 \%$ [4].

Anemia in the elderly is often under-recognized because they usually present with nonspecific symptoms such as tiredness and weakness, which are frequently assumed to be part of the aging process. Awareness of the effects of anemia is rising, as it has been shown to have poorer outcomes in geriatric patients, including increased risk of physical disability, cognitive impairment, hospitalization, and mortality $[3,5]$.

The etiology of anemia in elderly individuals is often more than one and may substantially aggravate the anemia, especially for acute hospitalized patients. The common causes of anemia include malnutrition; blood loss; endocrinologic and metabolic causes; a chronic inflammatory state, such as chronic kidney disease or cancer; un- 
explained, clonal, or drug-induced anemia; and increased consumption or destruction of erythrocytes [6]. Correction of anemia can not only provide symptom management but can also improve the activities of daily living (ADL) like toileting, mobility and dressing and clinical outcomes for hospitalized patients [7-9]. Studies have shown that treating anemia in specific patient groups decreases their length of stay or improves their function [10-13]. A cohort study of postoperative hip fracture geriatric patients with higher hb levels was independently associated with greater walking distance and functional recovery [14].

The hb threshold to trigger treatment for anemia in the elderly remains debatable. Attempts have been made to determine the optimal hb levels to guide management of anemia, including blood transfusion therapy. This strategy has been confounded by baseline function, hb level, and additional co-morbidities, including cardiovascular disease and risk of treatment. To the best of the authors' knowledge, there is scant evidence available to suggest an $\mathrm{hb}$ 'trigger' for treatment of anemia for rehabilitation and recovery purposes. The published guidelines [15-33] acknowledge patients' co-variables (including age) and other patient-specific criteria to be taken into consideration when making decisions for blood transfusion therapy. A consensus was reached on restrictive transfusion such that transfusion may be of benefit when the hb is less than 6-7 $\mathrm{g} / \mathrm{dL}$. However, for those with hb greater than $10 \mathrm{~g} / \mathrm{dL}$, correction of anemia is not beneficial, mainly for mortality benefit. Patients discharged with lower hb levels may have suboptimal functional recovery and quality of life [3439]. One of the strategies proposed for prudent anemia correction in the elderly is to keep hb thresholds at 9-10 g/ $\mathrm{dL}$ [40]. The aim of this study is to examine the effects of anemia and an hb threshold of $9 \mathrm{~g} / \mathrm{dL}$ on the rehabilitation outcome of patients in a subacute geriatric rehabilitation ward.

\section{Materials and methods}

\section{Study population}

Medical records were reviewed from January 2018 until April 2019 for all subjects admitted to the subacute geriatric ward in Taiping Hospital. The sample size was estimated using Open EPI software. The assumption was made that non-anemic subjects might have a $20 \%$ improvement in MBI relative to subjects with anemia. Preliminary unpublished data indicated that at least 20 subjects were needed in each group to demonstrate the assumption with a level of significance of 0.05 and a power of $80 \%$. According to previous data, the ratio of anemic subjects without transfusion was calculated as 1:5. The total number of subjects to be investigated to obtain the final study population was 167 . Subjects whose medical records were incomplete or missing their initial or final MBI $(n=26)$, those who were younger than 60 years of age $(n=10)$, or those who did not have hb on admission or one week prior or later $(n=5)$ were excluded from the study. After accounting for these criteria, a total of 126 subjects were included in this study.

Subacute geriatric wards provide multidisciplinary treatment modalities to subjects including doctors, nurses, physiotherapists, occupational therapists, speech and language therapists, and dieticians. The selection of subjects from the general ward to the subacute ward was made by dedicated geriatric doctors who deemed the patients to have strong potential for recovery based on the local setting criteria. Upon admission, subjects were assessed by all team members for an individualized plan. At least three hours of daily physiotherapy or occupational therapy was provided for all suitable subjects. The subjects' progress was reviewed and their plans were discussed during the multidisciplinary team meeting, which was held once per week until discharge.

\section{Hematological test results}

$\mathrm{Hb}$ levels and blood investigation results were collected on the day of admission. If there were no blood investigations on admission, laboratory results a week prior to or after admission to the subacute ward were traced from the pathology department.

\section{Functional assessment}

Subjects' functional status was assessed using a validated MBI by qualified occupational therapists on a weekly basis until discharge. The items could be divided into two groups, one related to self-care (feeding, grooming, bathing, dressing, toilet use, and bowel and bladder care) and the other related to mobility (ambulation, transfers, and stair climbing). With a maximum score of 100 , dependency levels were upgraded by every 20 points: total dependency (0-19), very dependent (20-39), partial dependency (40-59), minimal dependency (60-79), and independence (80-100) [41]. We used a cut-off point of 60, as it depicted the transition of subjects from dependency to assisted independence, with a marked likelihood of living in the community [42].

\section{Statistical analysis}

Statistical analysis was carried out by means of the IBM SPSS Statistics Version 21. Normally distributed data were compared with the $t$-test, and abnormally distributed data were compared with Fisher's exact and Mann-Whitney $U$ tests. Predictors for the outcome of the MBI were analyzed by multiple linear regression. A cut-off point of $P<0.05$ was taken for statistical significance.

\section{Results}

The demographic characteristics of the 126 subjects are summarized in Table 1 below. The results show that $43.7 \%$ of subjects $(n=55)$ were anemic; they had a higher creatinine level, with a mean of $188.9 \mathrm{umol} / \mathrm{L}$, and they had a lower albumin level of $30.2 \mathrm{~g} / \mathrm{dL}$, as compared with non-anemic subjects who had a mean creatinine of 92.7 umol/L and an albumin of $36.2 \mathrm{~g} / \mathrm{dL}(P<0.001$; Table 2$)$. The MBI for anemic subjects on admission was higher 
than for non-anemic subjects, but the difference was not significant $(P=0.059)$. Both groups were mainly in the partial dependency category (MBI was within 40-59) [41]. The MBI improvement for non-anemic subjects was significantly higher in non-anemic subjects $(P=0.021$; Table 2).

Subgroup analysis for the subjects' hb cut-off value of $9 \mathrm{~g} /$ $\mathrm{dL}$ is shown in Table 3. Individuals with hb levels of less than $9 \mathrm{~g} / \mathrm{dL}$ have significantly higher creatinine and lower albumin levels. Charlson comorbidity index $>2$ and clinical frailty scale $>5$ were not significantly different, but their MBIs on admission were significantly higher. Upon discharge, hb levels greater than $9 \mathrm{~g} / \mathrm{dL}$ were significantly associated with MBI improvement of more than 20 .

Simple linear regression found that the $P$-values were not significant for albumin, creatinine, the Charlson comorbidity index, or the clinical frailty scale. Otherwise, age, $\mathrm{hb}$, and admission MBI were significantly associated with
Table 1. Demographics of the Study Subjects $(n=126)$.

\begin{tabular}{ll}
\hline & $\boldsymbol{n}(\boldsymbol{\%})$ \\
\hline Age (years) & $44(34.9)$ \\
$60-69$ & $42(33.3)$ \\
$70-79$ & $40(31.8)$ \\
80 and older & \\
Sex & $52(41.3)$ \\
Male & $74(58.7)$ \\
Female & \\
Race & \\
Malay & $61(48.4)$ \\
Chinese & $46(36.5)$ \\
Indian & $18(14.3)$ \\
Other & $1(0.8)$ \\
\hline
\end{tabular}

Table 2. Variables Comparison for Anemic and Non-Anemic Subjects.

\begin{tabular}{|c|c|c|c|}
\hline & $\begin{array}{l}\text { Anemic } \\
(n=55)\end{array}$ & $\begin{array}{l}\text { Non-Anemic } \\
(n=71)\end{array}$ & $P$-value \\
\hline Age, Median (IQR) & $77(65,85)$ & $75(66,80)$ & $0.243^{*}$ \\
\hline \multicolumn{4}{|l|}{ Gender, $n(\%)$} \\
\hline Male & $17(13.5)$ & $35(27.8)$ & $0.036^{* *}$ \\
\hline Female & $38(30.2)$ & $36(28.5)$ & \\
\hline \multicolumn{4}{|l|}{ Race, $n(\%)$} \\
\hline Malay & $25(19.8)$ & $36(28.6)$ & $0.770 * *$ \\
\hline Chinese & $21(16.7)$ & $25(19.8)$ & \\
\hline Indian & $8(6.3)$ & $10(7.9)$ & \\
\hline Other & $1(0.9)$ & 0 & \\
\hline \multicolumn{4}{|l|}{ Biochemistry results, Mean (SD) } \\
\hline WBC & $9.7(3.7)$ & $10.9(4.5)$ & $0.113 * * *$ \\
\hline $\mathrm{MCV}$ & $85.5(12.0)$ & $86.4(8.8)$ & $0.662 * * *$ \\
\hline $\mathrm{MCH}$ & $29.8(9.5)$ & $29.9(6.4)$ & $0.946 * * *$ \\
\hline Platelet & $277.6(161.6)$ & $243.1(72.5)$ & $0.112 * * *$ \\
\hline Creatinine & $188.9(171.5)$ & $92.7(49.6)$ & $<0.001 * * *$ \\
\hline Albumin & $30.2(7.9)$ & $36.2(6.1)$ & $<0.001 * * *$ \\
\hline $\begin{array}{l}\text { Charlson Comorbidity Index }>2 \\
\text { (moderate-severe) }\end{array}$ & $52(42.6)$ & $70(53.4)$ & $0.317^{*}$ \\
\hline Clinical Frailty Scale $>5$ (moderate-severe) & $18(75.0)$ & $6(25.0)$ & $<0.001 * *$ \\
\hline Length of Stay (days), Median (IQR) & $9(6,14)$ & $11(7,15)$ & $0.166^{* * *}$ \\
\hline \multicolumn{4}{|l|}{ MBI Score, Median (IQR) } \\
\hline On admission & $47(29,63)$ & $36(21,59)$ & $0.059 * * *$ \\
\hline On discharge & $64(39,79)$ & $60(37,78)$ & $0.599 * * *$ \\
\hline Score Improvement & $8(1,18)$ & $14(5,26)$ & $0.021 * * *$ \\
\hline \multicolumn{4}{|l|}{$\begin{array}{l}\text { Number of subjects with the following MBI } \\
\text { Scores, } n(\%)\end{array}$} \\
\hline Initial Score $\geq 60$ & $17(50.0)$ & $17(50.0)$ & $0.422 * *$ \\
\hline Discharge score $\geq 60$ & $26(41.9)$ & $36(58.1)$ & $0.702 * *$ \\
\hline Score improvement $\geq 20$ & $9(25.0)$ & $27(75.0)$ & $0.008^{* *}$ \\
\hline
\end{tabular}

* Fisher's Exact Test, ** Mann-Whitney U Test, *** Pearson's Chi Square. 
rehabilitation outcome. Therefore, it was appropriate to draw a conclusion that albumin, creatinine, the Charlson comorbidity index and the clinical frailty scale were not significantly associated with rehabilitation outcomes.

\section{Discussion}

The prevalence of anemia in our study subjects was high $(43.7 \%)$ and comparable to a large population observational study [9] that reported that the prevalence of anemia was $46.8 \%$ in hospitalized older subjects. The hospitalized elderly population had a higher prevalence of anemia than the community-living elderly population $(35.5 \%)$ in Malaysia [2] because anemia was associated with higher comorbidity and poorer health status [3]. As shown in this study, anemic subjects had significantly lower albumin levels, higher creatinine levels, and a higher clinical frailty scale ( $>5$; Table 2 ). The majority of anemic subjects had normocytic normochromic anemia. A previous study suggested that anemia in elderly adults was more likely due to chronic illness than nutritional deficiencies [43]. As this was a cross-sectional survey, causative relationships and etiology of anemia could not be established.

The MBIs on admission were found to be higher in anemic subjects than in non-anemic subjects, but it was insignificant. However, it was significant in individuals with hemoglobin $<9 \mathrm{~g} / \mathrm{dL}$. This finding was in contrast with anemia, which was associated with a higher number of impaired ADLs upon hospital admission to the general ward [9]. The possible explanation was geriatrician selection bias; individuals with a presumed better potential for recovery were more likely to be admitted to subacute geriatric wards for active rehabilitation. Individuals with more comorbidities, poorer health status, and a baseline clinical frailty scale would not be subjected to subacute ward rehabilitation. Nonetheless, both groups were mainly in the partial dependency category (MBI was within 40-59) [41]. After treatment with active rehabilitation, there was a significant MBI improvement for all subjects of median 10 (IQR 3, 23; $P<0.001$ ). The number of subjects who were dependent $(\mathrm{MBI}<60)$ at admission was also re-

Table 3. Variables Comparison for $\mathrm{Hb}<9 \mathrm{~g} / \mathrm{dL}$ and $\mathrm{Hb} \geq 9 \mathrm{~g} / \mathrm{dL}$ Subjects.

\begin{tabular}{|c|c|c|c|}
\hline & $\begin{array}{l}\text { Hemoglobin }<9 \mathrm{~g} / \mathrm{dl}, \\
(n=15)\end{array}$ & $\begin{array}{l}\text { Hemoglobin } \geq 9 \mathrm{~g} / \mathrm{dl}, \\
(n=111)\end{array}$ & $P$-value \\
\hline Age, Median (IQR) & $77(65,84)$ & $75(66,83)$ & $0.114 *$ \\
\hline \multicolumn{4}{|l|}{ Gender, $n$ (\%) } \\
\hline Male & $3(2.4)$ & $49(38.9)$ & $0.075 * *$ \\
\hline Female & $12(9.5)$ & $62(49.2)$ & \\
\hline \multicolumn{4}{|l|}{ Race, $n(\%)$} \\
\hline Malay & $8(6.3)$ & $54(42.9)$ & $0.879 *$ \\
\hline Chinese & $6(4.8)$ & $39(31.0)$ & \\
\hline Indian & $1(0.8)$ & $17(13.5)$ & \\
\hline Other & $0(0)$ & $1(0.8)$ & \\
\hline \multicolumn{4}{|l|}{ Biochemistry results, Mean (SD) } \\
\hline WBC & $9.93(3.72)$ & $10.46(4.27)$ & $0.982 * * *$ \\
\hline $\mathrm{MCV}$ & $86.02(9.14)$ & $86.01(10.43)$ & $0.307 * * *$ \\
\hline $\mathrm{MCH}$ & $28.07(3.69)$ & $30.19(8.24)$ & $0.163 * * *$ \\
\hline Platelet & $260.00(162.20)$ & $257.95(114.72)$ & $0.590 * * *$ \\
\hline Creatinine & $274.93(178.98)$ & $115.95(107.19)$ & $<0.001 * * *$ \\
\hline Albumin & $26.00(9.10)$ & $34.47(6.78)$ & $0.002 * * *$ \\
\hline $\begin{array}{l}\text { Charlson Comorbidity Index }>2 \text { (moderate- } \\
\text { severe) }\end{array}$ & $16(13.1)$ & $106(86.9)$ & $1.000 *$ \\
\hline Clinical Frailty Scale > 5 (moderate-severe) & $9(9.4)$ & $87(90.6)$ & $0.076^{*}$ \\
\hline \multicolumn{4}{|l|}{ MBI Score, Median (IQR) } \\
\hline On admission & $55(39,77)$ & $39(25,59)$ & $0.020 * * *$ \\
\hline On discharge & $71(50,84)$ & $62(37,78)$ & $0.174 * * *$ \\
\hline \multicolumn{4}{|l|}{$\begin{array}{l}\text { Number of subjects with the following MBI } \\
\text { Scores, } n(\%)\end{array}$} \\
\hline Initial Score $\geq 60$ & $7(23.5)$ & $27(76.5)$ & $0.116^{* *}$ \\
\hline Discharge score $\geq 60$ & $9(14.5)$ & $56(85.5)$ & $0.587 * *$ \\
\hline Score improvement $\geq 20$ & $0(0)$ & $36(100)$ & $0.009 *$ \\
\hline
\end{tabular}

* Fisher's Exact Test, ** Pearson's Chi-Square, *** Mann-Whitney U Test. 
duced from $75.4 \%$ to $49.83 \%$ upon discharge $(P<0.001$; not included in table). The mean length of stay was 11 days $( \pm 5.7)$. These findings supported the role of short rehabilitation in the subacute geriatric ward, with a multidisciplinary team approach being the key element for successful rehabilitation. The time and effort invested was important to promoting recovery and independence in elderly subjects with multiple comorbidities to reduce institutionalization of these subjects and to reduce caregiver burden.

Non-anemic subjects had significantly higher MBI recovery than anemic subjects, as shown in Table $2(P=0.021)$. This finding was comparable with a large observational study that showed that anemic subjects had a lower rate of recovery than non-anemic subjects, and anemia was associated with a substantially lower likelihood of regaining independence after hospital discharge [9]. Subgroup analysis showed that a small number of subjects with an $\mathrm{hb} \geq 9 \mathrm{~g} / \mathrm{dL}$ had a significantly higher MBI improvement $\geq 20(P=0.009)$, as shown in Table 3 , and the finding was not confounded by albumin, creatinine, the Charlson comorbidity index, or the clinical frailty scale.

This finding suggested that the hb threshold of 9-10 might be adequate for elderly subjects, as suggested by another report [40]. Moderately anemic (hb 7.0-9.9 g/dL) subjects have few symptoms or no symptoms at all. This is because of body homeostasis mechanisms that preserve tissue perfusion to vital organs. These homeostasis mechanisms include increased blood circulation due to reduced blood viscosity, increased oxygen supply to tissues due to raised red cell 2,3-bisphosphoglycerate (2,3-BPG), increased plasma volume, and redistribution of blood flow [43]. In general, anemic subjects begin to experience symptoms of tiredness, shortness of breath, and palpitations only when the hb level is less than $7 \mathrm{~g} / \mathrm{dL}$ (about two-thirds of normal) as the basal cardiac output increases [44-46]. However, the elderly population, especially those with cardiovascular disease, may have impaired compensatory mechanisms. Elderly subjects with moderate anemia (hb 7.0-9.9 g/dL) have lost the compensatory mechanism of tachycardia and increased cardiac output, resulting in being more passive and demotivated for active rehabilitation. However, liberal strategy to target hb higher than $11.3 \mathrm{~g} / \mathrm{dL}$ did not improve post operation recovery of elderly patients with hip fracture frailty, as demonstrated in a randomize control trial [44].

In this study, the non-anemic group (or $\mathrm{hb} \geq 9 \mathrm{~g} / \mathrm{dL}$ ) did not have a significant difference in achieving an $\mathrm{MBI} \geq$ 60 , which they did not have a marked likelihood of living in the community [42]. This might imply that the improvement of MBI > 20 might ease the caregiver's burden and increase the patients' quality of life more than the subject's likelihood of living in the community.

\section{Conclusions}

A geriatric rehabilitation ward plays a significant role in facilitating the recovery of subjects to return to indepen- dent living in the community. In this study, non-anemic subjects showed significant MBI improvement. Our study also suggested that judicious practices to target an hb threshold of $9 \mathrm{~g} / \mathrm{dL}$ might be able to improve a subject's functional outcome. These results should encourage further research with a larger elderly population to provide insights and awareness for the need to diagnose and treat anemia in rehabilitation subjects.

\section{Declarations}

Acknowledgments: We would like to thank the DirectorGeneral of Health, Malaysia, for his permission to publish this article; and occupational therapists, physiotherapists, dieticians and nurses in Geriatric ward Hospital Taiping.

Authors' contributions: Conceptualization: Chin ML, Cheah WK. Methodology: Chin ML, Chan CWS, Chong HE. Formal analysis: Chin ML, Chan CWS. Project administration: Chin ML. Writing original draft: Chin ML. Writing review and editing: Chin ML, Cheah WK, Chan CWS, Chong HE. Approval of final manuscript: all authors.

Availability of data and materials: The data that support the findings of this study are available from the corresponding author (Chin ML) upon reasonable request.

Conflicts of interest: All authors declared that there are no conflicts of interest.

Ethics approval and consent to participate: Ethics approval was obtained from Medical Research and Ethics Committee, Ministry of Health Malaysia (Ref: NMRR19-1965-47705 (IIR)).

Consent for publication: The manuscript has been read and approved for submission by all the named authors for open access publishing.

\section{References}

1. Blanc B. Nutritional anemias. Report of a WHO scientific group. WHO Technical Report Series, 1968, 405: 1-40.

2. Yusof M, Awaluddin S M, Omar M, et al. Prevalence of Anaemia among the Elderly in Malaysia and Its Associated Factors: Does Ethnicity Matter? Journal of Environmental and Public Health, 2018, 2018: 1803025.

3. Röhrig G. Anemia in the frail, elderly patient. Clinical Interventions in Aging, 2016, 11: 319.

4. Tay M R J, Ong Y Y. Prevalence and risk factors of anaemia in older hospitalised patients. Proceedings of Singapore Healthcare, 2011, 20(2): 71-79.

5. Chalmers K A, Knuiman M W, Divitini M L, et al. Longterm mortality risks associated with mild anaemia in older persons: the Busselton Health Study. Age Ageing, 2012, 41(6): 759-764.

6. Stauder R, Valent P, Theurl I. Anemia at older age: etiologies, clinical implications, and management. Blood, 2018, 131(5): 505-514. 
7. Witkos M, Uttaburanont M, Lang C, et al. Effects of anemia on rehabilitation outcomes in elderly patients in the post-acute care setting. Topics in Geriatric Rehabilitation, 2009, 25(3): 222-230.

8. Maraldi C, Ble A, Zuliani G, et al. Association between anemia and physical disability in older patients: role of comorbidity. Aging Clinical and Experimental Research, 2006, 18(6): 485-492.

9. Maraldi C, Volpato S, Cesari M, et al. Anemia and recovery from disability in activities of daily living in hospitalized older persons. Journal of the American Geriatrics Society, 2006, 54(4): 632-636.

10. Penninx B W, Guralnik J M, Onder G, et al. Anemia and decline in physical performance among older persons. The American Journal of Medicine, 2003, 115(2): 104110.

11. Mancuso A, Migliorino M, De Santis S, et al. Correlation between anemia and functional/cognitive capacity in elderly lung cancer patients treated with chemotherapy. Annals of Oncology, 2006, 17(1): 146-150.

12. Silverberg D S, Wexler D, Blum M, et al. The use of subcutaneous erythropoietin and intravenous iron for the treatment of the anemia of severe, resistant congestive heart failure improves cardiac and renal function and functional cardiac class, and markedly reduces hospitalizations. Journal of the American College of Cardiology, 2000, 35(7): 1737-1744.

13. Silverberg D S, Wexler D, Sheps D, et al. The effect of correction of mild anemia in severe, resistant congestive heart failure using subcutaneous erythropoietin and intravenous iron: a randomized controlled study. Journal of the American College of Cardiology, 2001, 37(7): $1775-1780$.

14. Lawrence V A, Silverstein J H, Cornell J E, et al. Higher $\mathrm{Hb}$ level is associated with better early functional recovery after hip fracture repair. Transfusion, 2003, 43(12): 1717-1722.

15. Group KDIGOAW. KDIGO clinical practice guideline for anemia in chronic kidney disease. Kidney International Supplements, 2012, 2(4): 279-335.

16. Group E W. Guidelines for red blood cell and plasma transfusion for adults and children. Canadian Medical Association Journal, 1997, 156(11): S1.

17. Tinegate H, Birchall J, Gray A, et al. Guideline on the investigation and management of acute transfusion reactions Prepared by the BCSH Blood Transfusion Task Force. British Journal of Haematology, 2012, 159(2): 143-153.

18. Carson J L, Stanworth S J, Roubinian N, et al. Transfusion thresholds and other strategies for guiding allogeneic red blood cell transfusion. Cochrane Database of Systematic Reviews, 2016, (10).

19. Carson J L, Grossman B J, Kleinman S, et al. Red blood cell transfusion: a clinical practice guideline from the AABB. Annals of Internal Medicine, 2012, 157(1): 49-58.

20. Health NIo. Consensus conference. Perioperative red blood cell transfusion. The Journal of the American Medical Association, 1988, 260: 2700-2703.
21. Welch H G, Meehan K R, Goodnough L T. Prudent strategies for elective red blood cell transfusion. Annals of Internal Medicine, 1992, 116(5): 393-402.

22. Innes G. Guidelines for Red Blood Cells and Plasma Transfusion for Adults and Children: An Emergency Physician's Overview of the 1997 Canadian Blood Transfusion Guidelines: PART 1: Red Blood Cell Transfusion. Journal of Emergency Medicine, 1998, 16(1): 129-132.

23. Murphy M, Wallington T, Kelsey $\mathrm{P}$, et al. Guidelines for the clinical use of red cell transfusions. British Journal of Haematology, 2001, 113(1): 24-31.

24. Nuttall G A, Brost B C, Connis R T, et al. Practice guidelines for perioperative blood transfusion and adjuvant therapies: an updated report by the American Society of Anesthesiologists Task Force on Perioperative Blood Transfusion and Adjuvant Therapies. Anesthesiology, 2006, 105(1): 198-208.

25. Ferraris V A, Ferraris S P, Saha S P, et al. Perioperative blood transfusion and blood conservation in cardiac surgery: the Society of Thoracic Surgeons and The Society of Cardiovascular Anesthesiologists clinical practice guideline. The Annals of Thoracic Surgery, 2007, 83(5): S27-S86.

26. Napolitano L M, Kurek S, Luchette F A, et al. Clinical practice guideline: red blood cell transfusion in adult trauma and critical care. Critical Care Medicine, 2009, 37(12): 3124-3157.

27. Napolitano L M, Kurek S, Luchette F A, et al. Clinical practice guideline: red blood cell transfusion in adult trauma and critical care. The Journal of Trauma, 2009, 67: 1439-1442.

28. Rodgers G M, Becker P S, Blinder M, et al. Cancer-and chemotherapy-induced anemia. Journal of the National Comprehensive Cancer Network, 2012, 10(5): 628-53.

29. Simon T L, Alverson D C, AuBuchon J, et al. Practice parameter for the use of red blood cell transfusions: developed by the Red Blood Cell Administration Practice Guideline Development Task Force of the College of American Pathologists. Archives of Pathology \& Laboratory Medicine, 1998, 122(2): 130.

30. Shander A, Fink A, Javidroozi M, et al. Appropriateness of allogeneic red blood cell transfusion: the international consensus conference on transfusion outcomes. Transfusion Medicine Reviews, 2011, 25(3): 232-246. e53.

31. Stehling L C, Doherty D C, Faust R J, et al. Practice guidelines for blood component therapy: a report by the American Society of Anesthesiologists Task Force on Blood Component Therapy. Anesthesiology, 1996, 84(3): 732-747.

32. Australasian Society of Blood Transfusion. Clinical Practice Guidelines: Appropriate Use of Red Blood Cells. 2013.

33. National Blood Authority, Australia, Subject Blood Management Guidelines. 2013

34. So-Osman C, Nelissen R, Brand R, et al. Postoperative anemia after joint replacement surgery is not related to quality of life during the first two weeks postoperatively. Transfusion, 2011, 51(1): 71-81. 
35. Vuille-Lessard É, Boudreault D, Girard F, et al. Postoperative anemia does not impede functional outcome and quality of life early after hip and knee arthroplasties. Transfusion, 2012, 52(2): 261-270.

36. Jans $\emptyset$, Bandholm T, Kurbegovic S, et al. Postoperative anemia and early functional outcomes after fast-track hip arthroplasty: a prospective cohort study. Transfusion, 2016, 56(4): 917-925.

37. Koch C G, Li L, Sun Z, et al. Magnitude of anemia at discharge increases 30-day hospital readmissions. Journal of Patient Safety, 2017, 13(4): 202-206.

38. Choi Y J, Kim S-O, Sim J H, et al. Postoperative anemia is associated with acute kidney injury in patients undergoing total hip replacement arthroplasty: a retrospective study. Anesthesia \& Analgesia, 2016, 122(6): 1923-1928.

39. Pitter F T, Jørgensen C C, Lindberg-Larsen M, et al. Postoperative morbidity and discharge destinations after fast-track hip and knee arthroplasty in patients older than 85 years. Anesthesia \& Analgesia, 2016, 122(6): 1807-1815.

40. Goodnough L T, Schrier S L. Evaluation and management of anemia in the elderly. American Journal of Hematol- ogy, 2014, 89(1): 88-96.

41. Sinoff G, Ore L. The Barthel Activities of Daily Living Index: self-reporting versus actual performance in the old-old ( $\geq 75$ years). Journal of the American Geriatrics Society, 1997, 45(7): 832-836.

42. Granger C, Hamilton B, Gresham G. The stroke rehabilitation outcome study--Part I: General description. Archives of Physical Medicine and Rehabilitation, 1988, 69(7): 506-509.

43. Fairweather-Tait S J, Wawer A A, Gillings R, et al. Iron status in the elderly. Mechanisms of Ageing and Development, 2014, 136: 22-28.

44. Gregersen M, Borris L C, Damsgaard E M. Postoperative blood transfusion strategy in frail, anemic elderly patients with hip fracture: the TRIFE randomized controlled trial. Acta Orthopaedica, 2015, 86(3): 363-372.

45. Goodnough L T, Despotis G J, Hogue Jr C W, et al. On the need for improved transfusion indicators in cardiac surgery. The Annals of Thoracic Surgery, 1995, 60(2): 473480.

46. Finch C A. Oxygen transport in man. Chest, 1972, 61(2): 12S-3S.

Cite this article as: Chin M L, Chan C WS, Chong H E, et al. Association of anemia with rehabilitation outcomes for subacute geriatric rehabilitation patients in a secondary hospital in malaysia[J]. Aging Pathobiology and Therapeutics, 2021, 3(4): 127-133. 